\title{
A cross-sectional comparison of selected anthropometric, laboratory, and densitometric parameters in postmenopausal osteoporotic women with and without vertebral compression fractures
}

\author{
Piotr Sawicki ${ }^{1}$, Marek Tałałaj ${ }^{2}$, Katarzyna Życińska ${ }^{1,3}$, Wojciech S. Zgliczyński ${ }^{4}$, Waldemar Wierzba ${ }^{5,6}$ \\ ${ }^{1}$ Department of Rheumatology, Systemic Connective Tissue Diseases, and Rare Diseases, Central Clinical Hospital MSWiA, \\ Warsaw, Poland \\ ${ }^{2}$ Department of Geriatrics, Internal Medicine, and Metabolic Bone Diseases, Centre of Postgraduate Medical Education, Warsaw, \\ Poland \\ ${ }^{3}$ Department of Family Medicine, Medical University of Warsaw, Warsaw, Poland \\ ${ }^{4}$ School of Public Health, Centre of Postgraduate Medical Education, Warsaw, Poland \\ ${ }^{5}$ Central Clinical Hospital MSWiA in Warsaw, Warsaw, Poland \\ ${ }^{6}$ UHE Satellite Campus in Warsaw, University of Humanities and Economics in Łódź, Warsaw, Poland
}

\begin{abstract}
Introduction: Osteoporosis leads to an increased risk of vertebral compression fractures (VCFs). Most of them are spontaneous, which makes early diagnosis difficult. The aim of the study was to find parameters that distinguish osteoporotic women with and without vertebral compression fractures.

Material and methods: A total of 437 women with postmenopausal osteoporosis were enrolled to the study. Based on the results of densitometric vertebral fracture assessment, patients were divided into 2 groups: with $(n=193)$ and without $(n=244)$ VCFs. Then selected anthropometric, laboratory, and densitometric parameters as well as questionnaire data were compared.

Results: The following distinguishing factors were found among patients with VCFs in comparison to patients without such fractures: older age -73.93 years vs. 69.63 years $[\mathrm{p}(1)<0.001, \mathrm{p}(2)<0.001]$, shorter height $-1.56 \mathrm{~m}$ vs. $1.58 \mathrm{~m}[\mathrm{p}(4)<0.001]$, lower value of glomerular filtration rate (GFR) according to Cockcroft-Gault formula $-58.22 \mathrm{~mL} / \mathrm{min}$. vs. $66.25 \mathrm{~mL} / \mathrm{min}$. [p(1) $<0.025$, $\mathrm{p}(2)=0.002]$, lower peripheral blood haemoglobin and serum albumin concentration (OR $=1.24,95 \%$ CI: 1.02-1.51, $\mathrm{p}(5)=0.03$; OR $=2.29,95 \%$ CI: 1.09-4.80, $p(5)=0.03$, respectively), and higher 10-year risk of major osteoporotic fracture (FRAX MOF) $-12.01 \%$ vs. 9.69\% [p(1)<0.01, $\mathrm{p}(2)<0.001]$ and hip fracture (FRAX HIP) $-3.85 \%$ vs. $2.55 \%$ [p(1) $<0.01, \mathrm{p}(2)<0.001]$. In addition, among patients with VCFs a greater severity of back pain was found in the 11-grade scale of pain intensity - 6.12 vs. $4.29[\mathrm{p}(1)<0.001, \mathrm{p}(2)<0.001, \mathrm{p}(3)<0.001]$. The bone mineral content (BMC) and bone mineral density (BMD) of the hip were lower in patients with VCFs - 25.25 vs. $26.2 \mathrm{~g}$ and $0.72 \mathrm{~g} / \mathrm{cm}^{2} v s .0 .75 \mathrm{~g} / \mathrm{cm}^{2}$, respectively $[\mathrm{p}(4)=0.04$ and $\mathrm{p}(4)<0.001$, respectively].

Conclusions: Patients with VCFs were characterised by greater back pain intensity, higher fracture risk according to the FRAX calculator, and lower values of the following: GFR according to Cockcroft-Gault formula, peripheral blood haemoglobin and serum albumin concentration, and BMD of the hip. Further studies are required to validate the FRAX calculator to assess not only the risk of future fractures but also unrecognised VCFs. (Endokrynol Pol 2021; 72 (3): 191-197)
\end{abstract}

Key words: osteoporosis; spinal fractures; back pain; cross-sectional studies

\section{Introduction}

Osteoporosis is a chronic metabolic bone disease, leading to fractures, and it is estimated that osteoporosis affects 22 million women and 5.5 million men in the European Union [1]. With an ageing population, not only the medical but also the socioeconomic effect of osteoporosis will increase further, making it a major public health problem. Osteoporotic fractures can be classified as fractures occurring in locations such as the hip, proximal humerus, pelvis, distal radial bone, thoracic, and lumbar spine [2,3]. To consider a fracture as osteoporotic, it should be associated with low-energy injury $[4,5]$. In particular, osteoporotic fractures can occur spontaneously [6], without injury. These types of fractures occur most often in the thoracic and lumbar spine, and due to their inherent nature they cause great diagnostic difficulties [7]. It has been proven that the occurrence of the first vertebral compression fracture significantly increases the risk of subsequent fractures [8-10]; therefore, early diagnosis of vertebral compression fractures (VCFs) is very important [11]. 
However, considering the common prevalence of back pain among older people, including those with osteoporosis [12-16], frequently occurring fluctuations in pain intensity [17], as well as the potentially harmful radiation dose of numerous imaging tests, it seems important to look for additional differentiating factors in patients with and without VCFs [18]. The aim of the study was to find parameters that distinguish osteoporotic women with and without VCFs.

\section{Material and methods}

\section{Patients}

A total of 437 women with diagnosed postmenopausal osteoporosis based on WHO criteria [19], extended to patients with osteopaenia with T-score equal to or less than -1.5 in densitometric measurements of central skeleton bone mineral density (BMD) and a coexisting low-energy fracture in a major location [3], were recruited for the study. All patients were hospitalised in the Department of Geriatrics, Internal Medicine, and Metabolic Bone Diseases, Centre of Postgraduate Medical Education or remained under the care of an osteoporosis clinic. Patients with suspected or diagnosed secondary osteoporosis, including steroid-induced, as well as patients who suffered high-energy, non-osteoporotic vertebral fractures were excluded from the study. In addition, patients were not included in the study in the presence of severe scoliosis or overlapping calcifications or structures of the mediastinum and abdominal cavity, which preclude identification of the borders of vertebral bodies.

\section{Anthropometric, laboratory, and densitometric data}

Measurements of bone mineral density in the central skeleton were conducted for each subject. To identify VCFs, patients underwent vertebral fracture assessment of Th6-L4 vertebrae by dual-energy X-ray absorptiometry (DXA) using a Horizon $\mathrm{W}$ bone densitometer (Hologic, Inc., Bedford, MA, USA). To ensure repeatability of measurements, all tests were performed by the same qualified person using the same scanning mode. Before the DXA examination, each patient's height was measured in a standing position, without shoes, using a stadiometer with $1 \mathrm{~mm}$ accuracy. Weight was measured using a calibrated digital electronic weighing scale with an accuracy of \pm 100 grams. Based on the results of vertebral fracture assessment, patients were divided into 2 groups: with VCFs, regardless of the number of fractures $(n=193)$ and without $\mathrm{VCFs}(\mathrm{n}=244)$. In both groups selected anthropometric parameters (age, height, weight), laboratory parameters [peripheral blood haemoglobin, serum calcium, inorganic phosphate, albumin, 25-hydroxyvitamin $\mathrm{D}$, alkaline phosphatase, creatinine with glomerular filtration rate (GFR) calculated according to the Modification of Diet in Renal Disease (MDRD) and Cockcroft-Gault formula and daily urinary calcium excretion], and densitometric parameters were compared. In addition to vertebral fracture assessment and measurements of bone mineral density, densitometric examination of body composition was performed. Also, a questionnaire taking into account the severity of back pain in an 11-point scale of pain assessment, the tendency to stumble and have falls, and the maximum individual height was conducted. Based on the latter parameter, growth loss was calculated and compared. 322 of the 437 subjects answered the questions in the questionnaire, of whom 143 were with and 179 were without VCFs.

\section{Statistical analysis}

Statistical analysis was performed using Statistica data analysis software system — version 13.3 (TIBCO Software Inc., 3307 Hillview Avenue, Palo Alto, CA 94304, USA). Continuous data were presented as mean $\pm \mathrm{SD}$ and categorical data were presented in terms of percentage in Table 1 . For the variables without normal distribution or characterised by a heterogeneous variance despite the normality of the distribution, a nonparametric comparison was performed by 3 tests for each variable: the Kolmogorov-Smirnov test (indication p[1]), the Mann-Whitney U test (indication p[2]), and the Wald-Wolfowitz test (indication $\mathrm{p}$ [3]). For all examined intervalquotient variables, characterised by normal distribution (which was confirmed by the Shapiro-Wilk test), the homogeneity of variance was verified by the Leven and Brown-Forsythe test. For this type of variable a parametric comparison using the " $\mathrm{z}$ " test or Student's t-test was conducted (indication p[4]). The odds ratios (ORs) and 95\% confidence intervals (CIs) for selected variables using logistic regression were analysed (indication $\mathrm{p}[5]$ ). The chi-square test was used to assess the significance of the data in Table 2. The p-value $<0.05$ was considered as significant.

\section{Results}

\section{Anthropometric parameters}

Older age was identified among patients with VCFs (73.93 years \pm 9.95$)$ than without VCFs $(69.63$ years \pm 10.15$),(\mathrm{p}[1]<0.001, \mathrm{p}[2]<0.001)$. The significance of the difference in body weight between the groups was not shown, although its value was higher by an average of about 2 kilograms for the group without VCFs. A shorter stature was observed in patients with a history of vertebral fractures $(1.56 \mathrm{~m} \pm 0.06)$, compared to patients without VCFs (1.58 $\mathrm{m} \pm 0.07)$, $(\mathrm{p}[4]<0.001)$.

\section{Laboratory parameters}

Patients with VCFs had a lower GFR, calculated according to the Cockcroft-Gault formula $(58.22 \mathrm{~mL} / \mathrm{min} . \pm 20.80)$ than did patients without VCFs $(66.25 \mathrm{~mL} / \mathrm{min} . \pm 23.04)$, $(\mathrm{p}[1]<0.025$ and $\mathrm{p}[2]=0.002, \mathrm{OR}=0.98,95 \% \mathrm{CI}$ : $0.97-0.99, p[5]=0.002$ ) (Fig. 1). There was no difference between the groups regarding laboratory parameters such as alkaline phosphatase, phosphate, calcium, creatinine, and 25-hydroxyvitamin D serum concentration. Lower daily urinary calcium excretion was found in patients with VCFs $(145.12 \mathrm{mg} / 24 \mathrm{~h} \pm 84.70)$ compared to those without VCFs $(175.46 \pm 84.61)$, $(\mathrm{p}[2]=0.02)$. Peripheral blood haemoglobin (Fig. 2) and serum albumin concentration were lower among patients with VCFs $(\mathrm{OR}=1.24,95 \% \mathrm{CI}: 1.02-1.51, \mathrm{p}[5]=0.03 ; \mathrm{OR}=2.29$, 95\% CI: 1.09-4.80, p[5] $=0.03$, respectively).

\section{Densitometric parameters and questionnaire data}

A higher 10-year risk of major osteoporotic fracture (FRAX MOF) and hip fracture (FRAX HIP) for patients with VCFs has been demonstrated (Fig. 3) (12.01\% \pm 4.71 ; $3.85 \% \pm 2.52$, respectively) in comparison to patients without VCFs $(9.69 \% \pm 4.75 ; 2.55 \% \pm 1.85$, respectively), $(\mathrm{p}[1]<0.01$ and $\mathrm{p}[2]<0.001, \mathrm{OR}=1.11,95 \%$ CI: 1.06-1.16, p[5] < 0.001; p [1] < 0.01 and p[2] $<0.001$, $\mathrm{OR}=1.31,95 \%$ CI: 1.18-1.46, p[5] $<0.001$, respectively). 
Table 1. Comparison of statistically significant results of densitometric measurements among subjects with $(n=193)$ and without $(n=244)$ vertebral compression fractures $(V C F s)$

\begin{tabular}{|c|c|c|c|}
\hline Parameter & Subjects with VCFs & Subjects without VCFs & $\mathrm{p}$ value \\
\hline BMC — hip [g] & $25.25 \pm 4.70$ & $26.2 \pm 4.03$ & $p(4)=0.04$ \\
\hline BMD — hip [g/cm2] & $0.72 \pm 0.10$ & $0.75 \pm 0.09$ & $p(4)<0.001$ \\
\hline T-score - hip & $-1.78 \pm 0.80$ & $-1.55 \pm 0.76$ & $p(4)<0.001$ \\
\hline PR - hip (\%) & $76.49 \pm 9.89$ & $79.78 \pm 9.73$ & $p(4)<0.001$ \\
\hline BMD — femoral neck [g/cm2] & $0.61 \pm 0.08$ & $0.63 \pm 0$ & $\mathrm{p}(1)<0.05, \mathrm{p}(2)=0.01$ \\
\hline T-score — femoral neck & $-2.15 \pm 0.74$ & $-1.98 \pm 0.73$ & $\mathrm{p}(1)<0.025, \mathrm{p}(2)<0.01$ \\
\hline PR — femoral neck (\%) & $71.76 \pm 9.86$ & $74.16 \pm 9.41$ & $\mathrm{p}(1)<0.025, \mathrm{p}(2)<0.01$ \\
\hline BMD L1 [g/cm2] & $0.76 \pm 0.13$ & $0.74 \pm 0.11$ & $\mathrm{p}(1)<0.05, \mathrm{p}(2)<0.05$ \\
\hline BMD L3 [g/cm2] & $0.85 \pm 0.17$ & $0.83 \pm 0.14$ & $\mathrm{p}(1)<0.05$ \\
\hline BMD L1-L4 [g/cm2] & $0.83 \pm 0.14$ & $0.80 \pm 0.11$ & $\mathrm{p}(1)<0.05$ \\
\hline T-score L1 & $-1.98 \pm 1.19$ & $-2.22 \pm 0.96$ & $\mathrm{p}(2)<0.05$ \\
\hline T-score L3 & $-2.14 \pm 1.51$ & $-2.33 \pm 1.24$ & $p(1)<0.05$ \\
\hline T-score L1-L4 & $-1.98 \pm 1.30$ & $-2.21 \pm 1.03$ & $\mathrm{p}(1)<0.05$ \\
\hline PR L1 (\%) & $77.83 \pm 13.39$ & $74.96 \pm 10.53$ & $\mathrm{p}(2)<0.05$ \\
\hline PR L2 (\%) & $77.51 \pm 14.06$ & $76.44 \pm 10.88$ & $\mathrm{p}(3)<0.05$ \\
\hline PR L3 (\%) & $78.17 \pm 15.35$ & $76.15 \pm 12.25$ & $\mathrm{p}(1)<0.05$ \\
\hline PR L1-L4 (\%) & $78.93 \pm 13.29$ & $76.70 \pm 10.57$ & $\mathrm{p}(1)<0.05$ \\
\hline Z-score L1 & $0.00 \pm 1.27$ & $-0.41 \pm 1.08$ & $\mathrm{p}(1)<0.01$ \\
\hline Z-score L2 & $0.14 \pm 1.44$ & $-0.18 \pm 1.19$ & $\mathrm{p}(2)<0.05$ \\
\hline Z-score L3 & $0.19 \pm 1.64$ & $-0.24 \pm 1.36$ & $\mathrm{p}(2)<0.005$ \\
\hline Z-score L4 & $0.56 \pm 1.72$ & $0.16 \pm 1.50$ & $\mathrm{p}(2)=0.01$ \\
\hline Z-score L1-L4 & $0.27 \pm 1.45$ & $-0.17 \pm 1.20$ & $\mathrm{p}(1)<0.01$ \\
\hline
\end{tabular}

$\mathrm{BMC}$ — bone mineral content; BMD — bone mineral density; PR — percentage of measured bone mineral density in relation to peak BMD

Table 2. Frequency of stumbles and falls among subjects with $(n=143)$ and without $(n=179)$ vertebral compression fractures (VCFs)

\begin{tabular}{lcc}
\hline $\begin{array}{l}\text { Frequency of stumbles } \\
\text { and falls }\end{array}$ & $\begin{array}{c}\text { Subjects } \\
\text { with VCFs }\end{array}$ & $\begin{array}{c}\text { Subjects } \\
\text { without VCFs }\end{array}$ \\
\hline $\begin{array}{l}\text { Rarely } \\
\text { (less than once a week) }\end{array}$ & $128(89.51 \%)$ & $163(91.05 \%)$ \\
\hline Once a week & $4(2.80 \%)$ & $2(1.12 \%)$ \\
\hline $\begin{array}{l}\text { Not every day (but more } \\
\text { often than once a week) }\end{array}$ & $11(7.69 \%)$ & $11(6.15 \%)$ \\
\hline Every day & $0(0.00 \%)$ & $3(1.68 \%)$ \\
\hline
\end{tabular}

A comparison of statistically significant results of densitometric parameters is presented in Table 1. There was no difference between groups in the frequency of stumbles and falls, as shown in Table $2(p=0.658)$. In the DXA total body examination, there were no differences between groups in parameters such as the following: total weight, fat mass, muscle mass, total mass of bone and soft tissues, and percentage fat content in the upper and lower limbs, head, and trunk. The study

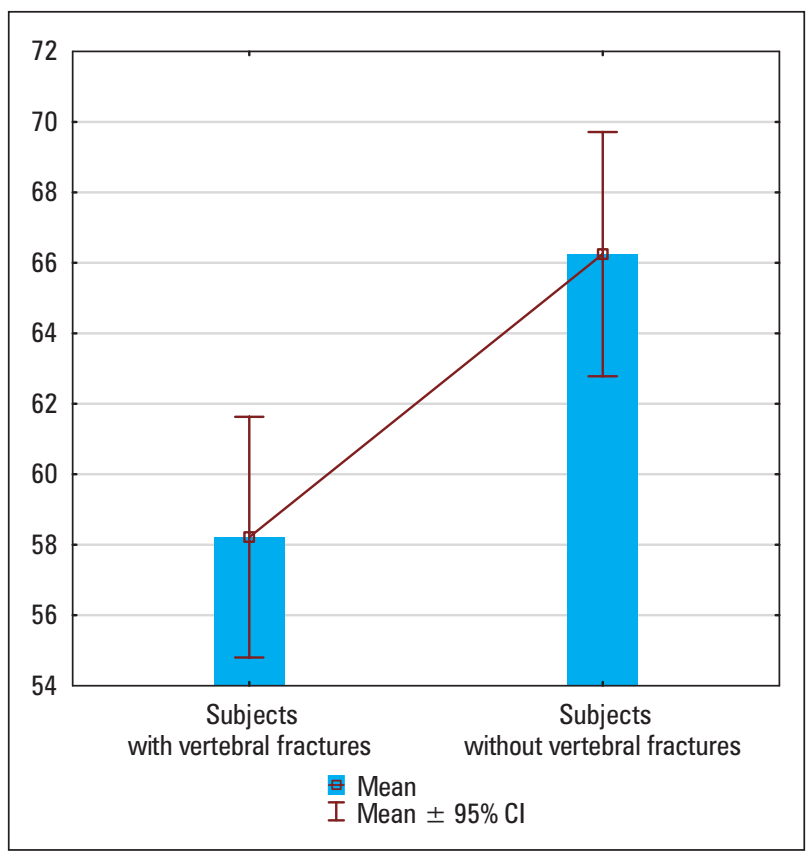

Figure 1. Glomerular filtration rate according to Cockcroft-Gault formula $(\mathrm{mL} / \mathrm{min})$ in subjects with and without vertebral compression fractures (VCFs) 


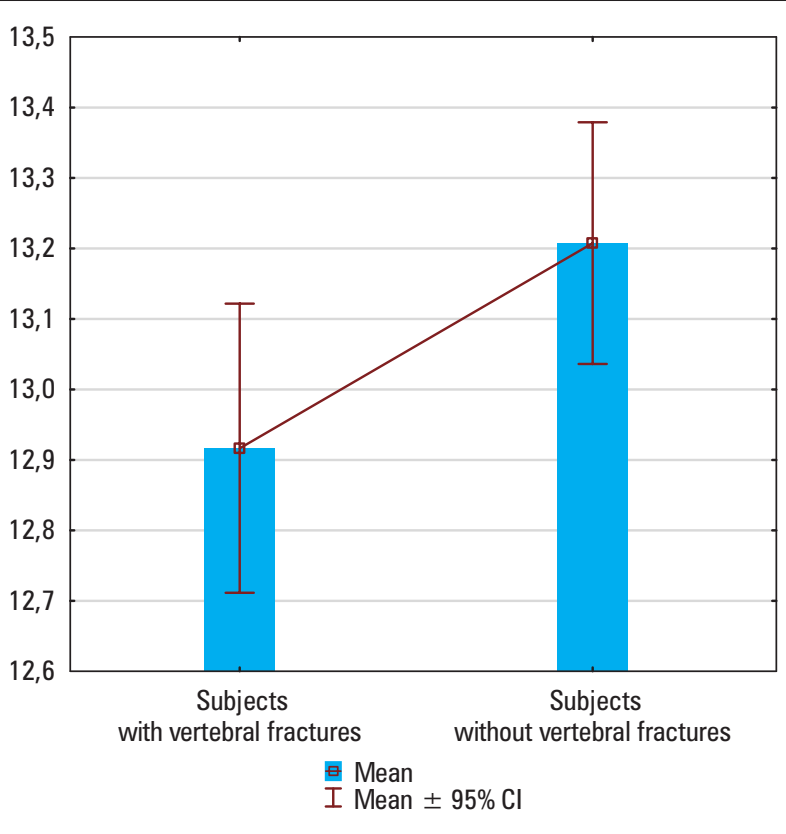

Figure 2. Peripheral blood haemoglobin concentration [g/dL] among subjects with and without vertebral compression fractures (VCFs)

groups also did not differ in terms of weight, volume, and surface of visceral adipose tissue, percentage of android and gynoid adipose tissue, as well as factors such as the following:

- the ratio of total body fat mass, expressed in kilograms, and the square of height, expressed in metres;

- the ratio of android and gynoid fat mass;

- the ratio of the percentage of body fat within the trunk and lower limbs;

- the ratio of the total soft tissue mass, expressed in kilograms, and the square of height, expressed in metres.

More severe back pain on an 11-point scale of pain intensity was found among patients with VCFs compared to those without $(6.12 \pm 2.09$ and $4.29 \pm 2.34$, respectively), $(\mathrm{p}[1]<0.001, \mathrm{p}[2]<0.001, \mathrm{p}[3]<0.001)$ (Fig. 3). Groups were not shown to differ in maximum individual height. We observed that patients with VCFs were characterised by greater growth loss - defined as the difference between maximum individual height and actual height $(0.0587 \mathrm{~m} \pm 0.039)$ - than subjects without VCFs $(0.0364 \mathrm{~m} \pm 0.026)$, $(\mathrm{p}[1]<0.001, \mathrm{p}[2]<0.001$, $\mathrm{p}[3]<0.001)$.

\section{Discussion}

Patients with VCFs were over 4 years older than subjects without such fractures. Older age significantly increases the likelihood of VCFs [20, 21], and this is

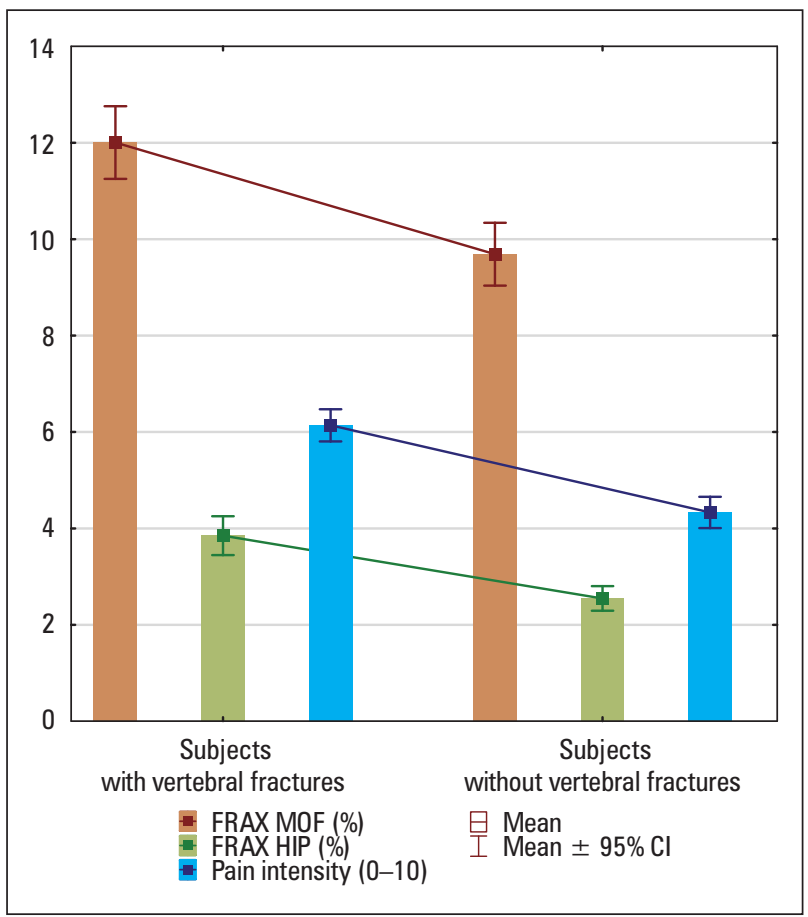

Figure 3. Pain intensity and 10-year risk of major osteoporotic fracture (FRAX MOF) and hip fracture (FRAX HIP) among subjects with and without vertebral compression fractures (VCFs)

related to the greater advancement of osteoporosis in older patients [22,23]. Subjects with previous VCFs were significantly shorter than patients without VCFs [24] and were characterised by much greater growth reduction [25]. Nevertheless, there was no significant difference between the groups in terms of maximum individual height; therefore, this parameter is irrelevant in the prediction of the presence of VCFs.

Due to the lack of differences between the groups in terms of total body weight as well as muscle mass, fat mass, and total bone mass, it can be concluded that the greater muscle mass, and thus better overall fitness and coordination, does not fulfil a protective role against VCFs [26]. Body fat content does not affect VCFs in any direction [27]. There is a cause-and-effect relationship: the lack of differentiation of groups in terms of total body weight and muscle mass causes a lack of differentiation in the degree of general fitness and coordination, which entails no significant difference in the frequency of stumbles and falls [26]. Therefore, injuries do not play a significant role in the prevalence of osteoporotic VCFs. In contrast to our results, in several reports the correlation between sarcopaenia [28, 29], visceral and subcutaneous adipose tissue [30], and increased risk of VCFs was confirmed.

A significantly lower value of GFR, calculated according to the Cockcroft-Gault formula, was found among patients with osteoporotic VCFs. The average 
difference between the groups was $>8 \mathrm{~mL} / \mathrm{min}$. The results obtained by the authors are consistent with previous studies, because the lower GFR calculated according to the Cockcroft-Gault formula, mostly recommended for the elderly, is associated with a higher prevalence of VCFs [31]. Interestingly, no significant difference was observed for isolated creatinine serum concentration or for GFR calculated according to the MDRD formula [32,33]. Irrespective of the glomerular filtration rate, among patients with type 2 diabetes association was demonstrated between albuminuria and higher frequency of VCFs [34]. The lack of differences in serum calcium and 25-hydroxyvitamin D concentration suggests that supplementation of calcium and vitamin D does not affect the likelihood of VCFs [35, 36]. Despite the significance of calcium and vitamin D supplementation in the course of osteoporosis, early diagnosis and the introduction of anti-resorptive therapy is most important to reduce the risk of VCFs [37]. The lower serum albumin concentration among patients with VCFs can be explained by the older age of these patients [38], but in the cross-sectional study performed by van der Jagt-Willems et al. [39], despite the lack of age difference between geriatric patients with and without VCFs, significantly lower serum albumin concentration among patients with VCFs was demonstrated. Several studies have shown an association between decreased haemoglobin level and an increased risk of non-vertebral fractures in men [40-42] as well as vertebral and non-vertebral fractures in women [42]. In addition, pernicious anaemia is associated with the prevalence of VCFs [43].

Reduced urinary calcium excretion in patients with VCFs can be explained by a higher frequency of anti-resorptive therapy used by these patients [44]. However, due to the small number of patients for whom this test was performed $(n=146)$ and the significant value obtained for only one statistical test, the result should be confirmed in further investigations.

According to parameters obtained from the densitometric examinations of the central skeleton, the higher bone mineral density of vertebral bodies in patients with VCFs is an obvious consequence of compression and condensing the same mass of bone mineral in a smaller volume [45] and does not contradict the proven relationship between reduced BMD of lumbar spine and increased risk of compression fractures [46]. Simultaneously in subjects with VCFs more advanced osteoporosis was confirmed by lower values of T-score of femoral neck and hip $[47,48]$.

The finding of a higher 10-year risk of major osteoporotic fracture and hip fracture among patients with VCFs confirms the results of previous studies [49] but can also be considered as a tool to assess the prob- ability of the present undiagnosed VCFs [50]. Due to the greater severity of back pain among patients with VCFs, these fractures should not be considered as asymptomatic or even oligosymptomatic. Because of the spontaneous and non-traumatic nature of this type of fractures, unawareness among patients, and often also among healthcare workers, of the high frequency of spontaneous VCFs in the course of osteoporosis and the common occurrence of back pain in older age, the severity of back pain is often underreported. Even if the severity of pain is reported by the patient, it is often associated with osteoarthritis. At the same time, it should not be assumed that the detected difference in the severity of pain is caused entirely by degenerative changes in patients with or without VCFs.

The main limitation of the study is to include only hospitalised patients or patients remaining under the care of one osteoporosis clinic, so results obtained by authors cannot be extended to the whole population. The size of the study group is relatively small, and further investigations are required to confirm our findings. However, this study is based on one of the first such surveys performed in Poland.

\section{Conclusions}

Among patients with diagnosed postmenopausal osteoporosis and the presence of VCFs, in comparison to patients without this type of fractures, the following were demonstrated: a significant loss of growth, lower GFR calculated according to Cockcroft-Gault formula, lower peripheral blood haemoglobin concentration and serum albumin concentration, lower BMD and T-score of femoral neck and hip in DXA examination, an increased 10-year risk of major osteoporotic fracture and hip fracture according to FRAX calculator, and at least moderate severity of back pain. Further studies are required to validate the FRAX calculator to assess not only the risk of future fractures but also unrecognised VCFs.

\section{Conflicts of interest}

All authors have no conflicts of interest to declare in relation to this article.

\section{Funding sources}

This study was self-financed.

\section{References}

1. Kanis JA, Cooper C, Rizzoli R, et al. European guidance for the diagnosis and management of osteoporosis in postmenopausal women. Osteoporosis Int. 2018; 30(1): 3-44, doi: 10.1007/s00198-018-4704-5, indexed in Pubmed: 30324412

2. Yoo JH, Moon SH, Ha YC, et al. Osteoporotic Fracture: 2015 Position Statement of the Korean Society for Bone and Mineral Research. J Bone Metab. 2015; 22(4): 175-181, doi: 10.11005/jbm.2015.22.4.175, indexed in Pubmed: 26713308. 
3. Lorenc R, Głuszko P, Franek E, et al. Guidelines for the diagnosis and management of osteoporosis in Poland : Update 2017. Endokrynol Pol. 2017; 68(5): 604-609, doi: 10.5603/EP.2017.0062, indexed in Pubmed: 29168548.

4. Curtis EM, Moon RJ, Harvey NC, et al. The impact of fragility fracture and approaches to osteoporosis risk assessment worldwide. Bone. 2017; 104: 29-38, doi: 10.1016/j.bone.2017.01.024, indexed in Pubmed: 28119181.

5. Alseddeeqi E, Bashir N, AlAli KF, et al. Characteristics of patients with low-trauma vertebral fractures in the United Arab Emirates: a descriptive multi-center analysis. Endocr J. 2020; 67(7): 785-791, doi: 10.1507/endocrj. EJ20-0013, indexed in Pubmed: 32238668

6. Gonzalez-Rodriguez E, Aubry-Rozier B, Stoll D, et al. Sixty spontaneous vertebral fractures after denosumab discontinuation in 15 women with early-stage breast cancer under aromatase inhibitors. Breast Cancer Res Treat. 2020; 179(1): 153-159, doi: 10.1007/s10549-019-05458-8, indexed in Pubmed: 31598815.

7. Kammerlander C, Zegg M, Schmid R, et al. Fragility fractures requiring special consideration: vertebral fractures. Clin Geriatr Med. 2014; 30(2): 361-372, doi: 10.1016/j.cger.2014.01.011, indexed in Pubmed: 24721374.

8. Balasubramanian A, Zhang J, Chen L, et al. Risk of subsequent fracture after prior fracture among older women. Osteoporos Int. 2019; 30(1): 79-92, doi: 10.1007/s00198-018-4732-1, indexed in Pubmed: 30456571.

9. Kendler DL, Chines A, Brandi ML, et al. The risk of subsequent osteoporotic fractures is decreased in subjects experiencing fracture while on denosumab: results from the FREEDOM and FREEDOM Extension studies. Osteoporos Int. 2019; 30(1): 71-78, doi: 10.1007/s00198-018-4687-2, indexed in Pubmed: 30244369.

10. Pluskiewicz W, Adamczyk P, Franek E, et al. The efficacy of pharmacotherapy in postmenopausal osteoporosis: a longitudinal observational study. Endokrynol Pol. 2019; 70(6): 473-477, doi: 10.5603/EP.a2019.0058, indexed in Pubmed: 31909456.

11. Song LJ, Wang LL, Ning L, et al. A modification and validation of quantitative morphometry classification system for osteoporotic vertebral compressive fractures in mainland Chinese. Osteoporos Int. 2018; 29(11): 2495-2504, doi: 10.1007/s00198-018-4641-3, indexed in Pubmed: 30030586.

12. Jones LD, Pandit H, Lavy C. Back pain in the elderly: a review. Maturitas. 2014; 78(4): 258-262, doi: 10.1016/j.maturitas.2014.05.004, indexed in Pubmed: 24974279.

13. Paolucci T, Morone G, Iosa M, et al. Efficacy of group-adapted physical exercises in reducing back pain in women with postmenopausal osteoporosis. Aging Clin Exp Res. 2014; 26(4): 395-402, doi: 10.1007/s40520-013-0183-x, indexed in Pubmed: 24338597.

14. Ramanathan S, Hibbert P, Wiles L, et al. What is the association between the presence of comorbidities and the appropriateness of care for low back pain? A population-based medical record review study. BMC Musculoskelet Disord. 2018; 19(1): 391, doi: 10.1186/s12891-018-2316-z, indexed in Pubmed: 30400874.

15. Francis RM, Aspray TJ, Hide G, et al. Back pain in osteoporotic vertebral fractures. Osteoporos Int. 2008; 19(7): 895-903, doi: 10.1007/s00198-007-0530-x, indexed in Pubmed: 18071648.

16. Moretti A, Gimigliano F, Di Pietro G, et al. Back pain-related disability and quality of life in patients affected by vertebral fractures: data from baseline characteristics of population enrolled in Denosumab In Real Practice (DIRP). Aging Clin Exp Res. 2015; 27 Suppl 1: S3-S9, doi: 10.1007/s40520-015-0428-y, indexed in Pubmed: 26210371.

17. Liu-Ambrose T, Eng JJ, Khan KM, et al. The influence of back pain on balance and functional mobility in 65- to 75-year-old women with osteoporosis. Osteoporos Int. 2002; 13(11): 868-873, doi: 10.1007/s001980200119, indexed in Pubmed: 12415433.

18. Clark EM, Hutchinson AP, McCloskey EV, et al. Lateral back pain identifies prevalent vertebral fractures in post-menopausal women: cross-sectional analysis of a primary care-based cohort. Rheumatology (Oxford). 2010; 49(3): 505-512, doi: 10.1093/rheumatology/kep414, indexed in Pubmed: 20015975.

19. Kanis JA, Glüer CC. An update on the diagnosis and assessment of osteoporosis with densitometry. Committee of Scientific Advisors, International Osteoporosis Foundation. Osteoporos Int. 2000; 11(3): 192-202, doi: 10.1007/s001980050281, indexed in Pubmed: 10824234

20. Li Y, Yan L, Cai S, et al. The prevalence and under-diagnosis of vertebral fractures on chest radiograph. BMC Musculoskelet Disord. 2018; 19(1): 235, doi: 10.1186/s12891-018-2171-y, indexed in Pubmed: 30021567.

21. Vokes TJ, Gillen DL, Pham AT, et al. Risk factors for prevalent vertebral fractures in black and white female densitometry patients. J Clin Densitom. 2007; 10(1): 1-9, doi: 10.1016/j.jocd.2006.11.002, indexed in Pubmed: 17289520 .

22. Bijlsma AY, Meskers CGM, Westendorp RGJ, et al. Chronology of age-related disease definitions: osteoporosis and sarcopenia. Ageing Res Rev. 2012; 11(2): 320-324, doi: 10.1016/j.arr.2012.01.001, indexed in Pubmed: 22306229.

23. Pietschmann P, Rauner M, Sipos W, et al. Osteoporosis: an age-related and gender-specific disease--a mini-review. Gerontology. 2009; 55(1): 3-12, doi: 10.1159/000166209, indexed in Pubmed: 18948685.
24. Yoh K, Kuwabara A, Tanaka K. Detective value of historical height loss and current height/knee height ratio for prevalent vertebral fracture in Japanese postmenopausal women. J Bone Miner Metab. 2014; 32(5): 533-538, doi: 10.1007/s00774-013-0525-y, indexed in Pubmed: 24122280.

25. Siminoski K, Jiang G, Adachi JD, et al. Accuracy of height loss during prospective monitoring for detection of incident vertebral fractures. Osteoporos Int. 2005; 16(4): 403-410, doi: 10.1007/s00198-004-1709-z, indexed in Pubmed: 15309381.

26. Cangussu-Oliveira LM, Porto JM, Freire Junior RC, et al. Association between the trunk muscle function performance and the presence of vertebral fracture in older women with low bone mass. Aging Clin Exp Res. 2020; 32(6): 1067-1076, doi: 10.1007/s40520-019-01296-2, indexed in Pubmed: 31471893.

27. Takata S, Yasui N. Effects of constitution, atraumatic vertebral fracture and aging on bone mineral density and soft tissue composition in women. J Med Invest. 2002; 49(1-2): 18-24, indexed in Pubmed: 11901755.

28. Di Monaco M, Castiglioni C, Bardesono F, et al. Sarcopenia, osteoporosis and the burden of prevalent vertebral fractures: a cross-sectiona study of 350 women with hip fracture. Eur J Phys Rehabil Med. 2020; 56(2): 184-190, doi: 10.23736/S1973-9087.20.05991-2, indexed in Pubmed: 32052946.

29. Wang WF, Lin CW, Xie CN, et al. The association between sarcopenia and osteoporotic vertebral compression refractures. Osteoporos Int. 2019; 30(12): 2459-2467, doi: 10.1007/s00198-019-05144-x, indexed in Pubmed: 31482304

30. Crivelli M, Chain A, da Silva ITF, et al. Association of Visceral and Subcutaneous Fat Mass With Bone Density and Vertebral Fractures in Women With Severe Obesity. J Clin Densitom. 2020 [Epub ahead of print], doi: 10.1016/j.jocd.2020.10.005, indexed in Pubmed: 33109469.

31. Yendt ER, Cohanim M, Jarzylo S, et al. Reduced creatinine clearance in primary osteoporosis in women. J Bone Miner Res. 1993; 8(9): 1045-1052, doi: 10.1002/jbmr.5650080904, indexed in Pubmed: 8237473.

32. Prasad B, Ferguson T, Tangri N, et al. Association of Bone Mineral Density With Fractures Across the Spectrum of Chronic Kidney Disease: The Regina CKD-MBD Study. Can J Kidney Health Dis. 2019; 6: 2054358119870539, doi: 10.1177/2054358119870539, indexed in Pubmed: 31467681

33. Elliott MJ, James MT, Quinn RR, et al. Estimated GFR and fracture risk: a population-based study. Clin J Am Soc Nephrol. 2013; 8(8): 1367-1376, doi: 10.2215/CJN.09130912, indexed in Pubmed: 23660179

34. Chung DJ, Choi HJ, Chung YS, et al. The prevalence and risk factors of vertebral fractures in Korean patients with type 2 diabetes. J Bone Miner Metab. 2013; 31(2): 161-168, doi: 10.1007/s00774-012-0398-5, indexed in Pubmed: 23076296

35. Jackson RD, LaCroix AZ, Gass M, et al. Women's Health Initiative Investigators. Calcium plus vitamin D supplementation and the risk of fractures. N Engl J Med. 2006; 354(7): 669-683, doi: 10.1056/NEJMoa055218, indexed in Pubmed: 16481635

36. Marwaha RK, Tandon N, Gupta Y, et al. The prevalence of and risk factors for radiographic vertebral fractures in older Indian women and men: Delhi Vertebral Osteoporosis Study (DeVOS). Arch Osteoporos. 2012; 7 201-207, doi: 10.1007/s11657-012-0098-8, indexed in Pubmed: 23225298.

37. Bauer DC, Black DM, Bouxsein ML, et al. Foundation for the National Institutes of Health (FNIH) Bone Quality Project. Treatment-Related Changes in Bone Turnover and Fracture Risk Reduction in Clinical Trials of Anti-Resorptive Drugs: A Meta-Regression. J Bone Miner Res. 2018; 33(4): 634-642, doi: 10.1002/jbmr.3355, indexed in Pubmed: 29318649.

38. Gom I, Fukushima H, Shiraki M, et al. Relationship between serum albumin level and aging in community-dwelling self-supported elderly population. J Nutr Sci Vitaminol (Tokyo). 2007; 53(1): 37-42, doi: 10.3177/jnsv.53.37, indexed in Pubmed: 17484377.

39. van der Jagt-Willems HC, van Hengel M, Vis M, et al. Why do geriatric outpatients have so many moderate and severe vertebral fractures? Exploring prevalence and risk factors. Age Ageing. 2012; 41(2): 200-206, doi: 10.1093/ageing/afr174, indexed in Pubmed: 22217460.

40. Jørgensen L, Skjelbakken T, Løchen ML, et al. Anemia and the risk of non-vertebral fractures: the Tromsø Study. Osteoporos Int. 2010; 21(10) 1761-1768, doi: 10.1007/s00198-009-1131-7, indexed in Pubmed: 19957163

41. Valderrábano RJ, Lee J, Lui LY, et al. Osteoporotic Fractures in Men (MrOS) Study Research Group. Older Men With Anemia Have Increased Fracture Risk Independent of Bone Mineral Density. J Clin Endocrinol Metab. 2017; 102(7): 2199-2206, doi: 10.1210/jc.2017-00266, indexed in Pubmed: 28368469

42. Lee EAe, Shin DW, Yoo JH, et al. Anemia and Risk of Fractures in Older Korean Adults: A Nationwide Population-Based Study. J Bone Miner Res. 2019; 34(6): 1049-1057, doi: 10.1002/jbmr.3675, indexed in Pubmed: 30690784

43. Goerss JB, Kim CH, Atkinson EJ, et al. Risk of fractures in patients with pernicious anemia. J Bone Miner Res. 1992; 7(5): 573-579, doi: 10.1002/jbmr.5650070514, indexed in Pubmed: 1615763.

44. Hohman EE, McCabe GP, Peacock M, et al. Validation of urinary calcium isotope excretion from bone for screening anabolic 
therapies for osteoporosis. Osteoporos Int. 2014; 25(10): 2471-2475, doi: 10.1007/s00198-014-2790-6, indexed in Pubmed: 24969137.

45. Lajlev SE, Rejnmark L, Harsløf T. T-score differences and nonprogression in lumbar vertebrae as predictors of vertebral fractures. Clin Endocrinol (Oxf). 2019; 91(1): 58-62, doi: 10.1111/cen.13987, indexed in Pubmed: 30973641.

46. Lee JE, Kim KM, Kim LK, et al. Comparisons of TBS and lumbar spine BMD in the associations with vertebral fractures according to the T-scores: A cross-sectional observation. Bone. 2017; 105: 269-275, doi: 10.1016/j.bone.2017.09.017, indexed in Pubmed: 28963079.

47. Johansson L, Sundh D, Zoulakis M, et al. The Prevalence of Vertebral Fractures Is Associated With Reduced Hip Bone Density and Inferior Peripheral Appendicular Volumetric Bone Density and Structure in Older
Women. J Bone Miner Res. 2018; 33(2): 250-260, doi: 10.1002/jbmr.3297, indexed in Pubmed: 28926125.

48. Lopes JB, Danilevicius CF, Takayama L, et al. Prevalence and risk factors of radiographic vertebral fracture in Brazilian community-dwelling elderly. Osteoporos Int. 2011; 22(2): 711-719, doi: 10.1007/s00198-010-1258-6, indexed in Pubmed: 20442985.

49. Donaldson MG, Palermo L, Ensrud KE, et al. FRAX and risk of vertebral fractures: the fracture intervention trial. J Bone Miner Res. 2009; 24(11): 1793-1799, doi: 10.1359/jbmr.090511, indexed in Pubmed: 19419318.

50. Cano A, Baró F, Fernández C, et al. Evaluation of the risk factors of asymptomatic vertebral fractures in postmenopausal women with osteopenia at the femoral neck. Maturitas. 2016; 87: 95-101, doi: 10.1016/j. maturitas.2016.02.014, indexed in Pubmed: 27013295. 